\title{
Inhibition of survivin enhances radiosensitivity of esophageal cancer cells by switching radiation- induced senescence to apoptosis
}

This article was published in the following Dove Press journal:

OncoTargets and Therapy

\author{
Xianghe Liu' \\ Yahui Zhao' \\ Weina Zhang' \\ Yang Gao' \\ Miaomiao Huo \\ Mei Liu' \\ Zefen Xiao ${ }^{2}$ \\ Shufang Liang ${ }^{3}$ \\ Ningzhi $\mathrm{Xu}^{1,3}$ \\ Hongxia Zhu' \\ 'Laboratory of Cell and Molecular \\ Biology \& State Key Laboratory of \\ Molecular Oncology, National Cancer \\ Center/Cancer Hospital, Chinese \\ Academy of Medical Sciences and \\ Peking Union Medical College, Beijing, \\ China; ${ }^{2}$ Department of Radiation \\ Oncology, National Cancer Center/ \\ Cancer Hospital, Chinese Academy \\ of Medical Sciences and Peking Union \\ Medical College, Beijing, China; ${ }^{3}$ State \\ Key Laboratory of Biotherapy and \\ Cancer Center, West China Hospital, \\ Collaborative Innovation Center \\ for Biotherapy, Sichuan University, \\ Chengdu, China
}

Correspondence: Hongxia Zhu Laboratory of Cell and Molecular Biology \& State Key Laboratory of Molecular Oncology, National Cancer Center/Cancer Hospital, Chinese Academy of Medical Sciences and Peking Union Medical College, 17 Panjiayuan Nanli, Chaoyang District, Beijing I0002I, China

Tel/fax +86 I0 67738220

Email drhxzhu@cicams.ac.cn
Purpose: Strategies to increase radiosensitivity are urgently needed. Combining radiosensitizing reagents with radiotherapy could improve the outcome of cancer treatment. Some preclinical studies showed that sepantronium bromide (YM155) could sensitize cancer cells to radiation by inhibiting the survivin protein. In this study, we try to investigate the function of YM155 on radiosensitivity of esophageal squamous cell carcinoma (ESCC) cells.

Materials and methods: ESCC cell lines were treated with radiation and YM155, and the radiation efficacy was evaluated by cell counting kit- 8 assay and clonogenic survival assay. Cell senescence was measured by senescence-associated $\beta$-galactosidase staining. Terminal deoxynucleotidyl transferase-mediated dUTP nick end-labeling assay, fluorescein isothiocyanatelabeled Annexin V/propidium iodide assay, and poly ADP-ribose polymerase cleavage were used to detect apoptosis. KYSE150 xenografts model was used to test the efficacy of radiation combined with YM155.

Results: YM155 could inhibit the upregulation of survivin induced by radiation in all ESCC cell lines, but the efficacy of radiosensitization varied in different cell lines. Radiation-induced senescence in KYSE150 and KYSE410 cells, and the combination with YM155 inhibited senescence and promoted apoptosis of ESCC cells, thereby enhancing radiosensitivity. Combination with YM155 and radiation delayed the growth of KYSE150 xenografts in nude mice by switching radiation-induced senescence to apoptosis. When p21 was inhibited in KYSE150 cells, radiation did not induce senescence, and the radiosensitization of YM155 was also attenuated. In KYSE510 and KYSE180 cells, radiation did not induce senescence, and YM155 could not enhance the radiosensitivity.

Conclusion: Our results suggest a new mechanism that YM155 might sensitize ESCC cells to radiation by switching radiation-induced senescence to apoptosis. The major determinant of radiosensitization by YM155 might be the induction of senescence by radiation.

Keywords: survivin, YM155, senescence, radiosensitivity, esophageal squamous cell carcinoma

\section{Introduction}

Esophageal cancer is a common cancer in China that is reported to have an incidence rate of 477.9 per 100,000 in $2015 .{ }^{1}$ Surgery is the primary treatment for esophageal cancer; however, radiotherapy and chemotherapy are also widely used in combination based on the clinical stage..$^{2-4}$ Radiotherapy is usually combined with chemotherapy and targeted therapy in the clinic. However, the radiotherapeutic effect remains unsatisfactory, and radioresistance is highly common in clinical treatment, leading to possible treatment failure. Therefore, strategies to increase radiosensitivity are urgently needed. 
Radiation mainly induces DNA damage, following which cells enter apoptosis, necrosis, mitotic catastrophe, autophagy, cell cycle arrest, and/or senescence. ${ }^{5}$ Several aspects of these pathways contribute to the effects of radiotherapy, such as p53, ${ }^{6}$ EGFR, ${ }^{7}$ miRNAs, ${ }^{8}$ and certain immune factors. ${ }^{9}$ Several approaches have been evaluated to enhance the efficiency of radiotherapy. MiR-338-5p enhanced the radiosensitivity of esophageal squamous cell carcinoma (ESCC) by inducing apoptosis through targeting survivin. ${ }^{10}$ Downregulation of $R O G D I$ can mediate radiosensitivity by blocking cells at $\mathrm{G} 2 / \mathrm{M}$, the most radiosensitive phase of the cell cycle. ${ }^{11}$ Sunitinib sensitized ESCC cells to radiation by inducing DNA double-strand breaks. ${ }^{12}$ Cordycepin produced radiosensitization by inducing p53-mediated apoptosis and modulating the expression of cell cycle checkpoint molecules. ${ }^{13}$ However, to date, notably few approaches have advanced to clinical trials.

Survivin is a multifunctional protein involved in apoptosis, cell division, and senescence. ${ }^{14,15}$ Survivin is overexpressed in multiple types of cancers, and survivin overexpression predicts resistance to chemotherapy and radiotherapy. ${ }^{16,17}$ Survivin appears to be an attractive target in cancer treatment, and various strategies have been used to target survivin. ${ }^{18,19}$ YM155 is the first small-molecule inhibitor to be developed, which could inhibit survivin expression by inhibiting the survivin upstream transcription factor Sp1. ${ }^{20}$ YM155 has been tested in clinical studies as a single agent or combined with chemotherapy. ${ }^{21-23}$

Recently, some preclinical studies showed that YM155 could sensitize cancer cells to radiation by inhibiting the survivin protein. The molecular mechanism included inhibition of DNA repair, enhancement of apoptosis, and abrogation of G2 checkpoint. ${ }^{24-26}$ We previously reported that a high expression of survivin predicts poor prognosis in ESCC following radiotherapy. ${ }^{27}$ In this study, we investigated the function of YM155 in sensitizing ESCC cells to radiation in vitro and in vivo. We observed that YM155 treatment led to different consequences in different ESCC cell lines and concluded that the molecular mechanism contributed to the difference in efficacies. Our results provided an evidence for the potential use of YM155 in certain cancers to enhance radiosensitivity.

\section{Materials and methods Cell culture and transfection}

The human ESCC cell lines KYSE150, KYSE410, KYSE180, and KYSE510, generously provided by Dr Yutaka Shimada, ${ }^{28}$ were cultured in RPMI1640 medium containing 10\% fetal bovine serum and supplemented with $100 \mathrm{U} / \mathrm{mL}$ penicillin and $100 \mu \mathrm{g} / \mathrm{mL}$ streptomycin at $37^{\circ} \mathrm{C}$ with $5 \% \mathrm{CO}_{2}$.
Transfection was performed in $70 \%-80 \%$ confluent cells using Attractene Transfection Reagent (Qiagen, Valencia, CA, USA) according to the manufacturer's instructions.

\section{Reagents and plasmids}

Sepantronium bromide (YM155) was purchased from Selleck Chemicals (Houston, TX, USA). For in vitro experiments, YM155 was dissolved in saline and diluted with culture medium. For in vivo experiments, YM155 was dissolved and diluted in saline immediately before administration. pSilencer3.0H1-shRNA-p21 was constructed as described previously. $^{29}$

\section{Cell viability analysis}

A total of $4 \times 10^{3}$ cells/well were seeded in 96-well plates, incubated overnight, and treated with YM155 at various concentrations $(0,5,10,25,50$, and $100 \mathrm{nmol} / \mathrm{L})$. Fortyeight hours later, cell viability was assessed using the cell counting kit-8 (CCK-8) assay (Dojindo, Kumamoto, Japan). The absorbance was determined at $450 \mathrm{~nm}$ using an iMark microplate reader (Bio-Rad Laboratories Inc., Hercules, CA, USA) according to the manufacturer's instructions.

\section{Clonogenic survival}

The ESCC cells were seeded at a density of $\sim 5 \times 10^{2}$ cells per well into 6-well plates. After cell adhesion, the cells were treated with YM155 for $24 \mathrm{~h}$ and subjected to irradiation with 4 Gy X-rays. The cells were later washed with PBS for three times, cultured in drug-free medium for $\sim 10$ days, fixed with methanol, and stained with Giemsa (Solarbio Life Sciences, Beijing, China). Only colonies containing more than 50 cells were scored. All experiments were conducted at least three times.

\section{Western blot analysis}

Cells were harvested and washed in PBS, homogenized in radio immunoprecipitation assay buffer (Cell Signaling Technology, Danvers, MA, USA), and centrifuged at $14,000 \times g$ for $15 \mathrm{~min}$ at $4^{\circ} \mathrm{C}$. After the concentrations were determined using a BCA Protein Quantification Kit (Thermo Fisher Scientific, Waltham, MA, USA), the extracted proteins were separated by SDS-PAGE and transferred to nitrocellulose membranes. The membranes were blocked with Tris-buffered saline with Tween 20 (TBS-T) buffer containing 5\% nonfat milk for $1 \mathrm{~h}$ at room temperature and incubated overnight at $4^{\circ} \mathrm{C}$ with the following primary antibodies: survivin $(1: 1,000$; Cell Signaling Technology), p53 (1:1,000; Proteintech), p21 (1:1,000; Proteintech), poly ADP-ribose polymerase 
(PARP) (1:1,000; Cell Signaling Technology), $\beta$-actin (Sigma-Aldrich Co., St Louis, MO, USA), and caspase-8 (1:1,000; Cell Signaling Technology). After being washed with TBS-T buffer, the membranes were incubated with secondary antibodies (ZSGB Biotechnology, Beijing, China) for $1 \mathrm{~h}$ at room temperature. The signals were detected using detection reagents (Engreen Biosystem Co. Ltd., Beijing, China) according to the manufacturer's instructions.

\section{Senescence-associated $\beta$-galactosidase (SA- $\beta-G a l)$ detection}

Cells treated under different conditions were subjected to SA- $\beta$-Gal staining using the Senescence Cells Staining Kit (Sigma-Aldrich Co.). Briefly, after being washed with PBS for three times, the cells were fixed with a fixative solution for 5-10 min followed by incubation with the staining solution at $37^{\circ} \mathrm{C}$ for $2-24 \mathrm{~h}$. Green-stained senescent cells were identified under a light microscope (Olympus CX41).

\section{Annexin V-FITC/PI assay}

For the fluorescein isothiocyanate (FITC)-labeled annexin V (Annexin V-FITC)/PI (propidium iodide) assay, we used the Apoptosis Detection Kit (BD Biosciences, San Jose, CA, USA). In brief, the cells were collected by trypsinization and washed with PBS for three times. After centrifugation at $120 \times g$, the cells were suspended and incubated with $1 \mathrm{~mL}$ of Annexin V-FITC solution for $30 \mathrm{~min}$ at room temperature in dark, and PI was added to a final concentration of $1 \mathrm{mg} / \mathrm{mL}$. The samples were then analyzed by flow cytometer LSR II (BD Biosciences) using the FlowJo software (Tree Star Inc., Ashland, OR, USA).

\section{Terminal deoxynucleotidyl transferase- mediated dUTP nick end-labeling (TUNEL) assay}

Apoptosis was detected using the In Situ Cell Death Detection Kit, AP (Hoffman-La Roche Ltd., Basel, Switzerland). In brief, fixed cells or frozen slides were permeabilized with TritonX-100 in $0.1 \%$ sodium citrate for $2 \mathrm{~min}$ on ice. The slides were later incubated with TdT enzyme at $37^{\circ} \mathrm{C}$ for $1 \mathrm{~h}$ and exposed to Converter-AP at $37^{\circ} \mathrm{C}$ for $30 \mathrm{~min}$, after which the samples were incubated with the substrate solution for $10 \mathrm{~min}$ at $15^{\circ} \mathrm{C}-25^{\circ} \mathrm{C}$ in the dark. The labeling on the cells was examined by light microscopy (Olympus CX41).

\section{Immunohistochemistry staining}

Sections ( $5 \mu \mathrm{m}$ thick) of paraffin-embedded tissue were placed on glass slides, rehydrated, incubated with $3 \%$ hydrogen peroxide to quench endogenous peroxidase activity, and blocked by incubation with $5 \%$ bovine serum albumin in PBS. The sections were subsequently incubated with the survivin (1:200; Cell Signaling Technology) and p21 (1:200; Proteintech) antibodies. After washing, the slides were incubated with horseradish peroxidase-conjugated anti-rabbit secondary antibody for $1 \mathrm{~h}$ at room temperature. The slides were incubated with 3,3'-diaminobenzidine (ZSGB Biotechnology) and counterstained with hematoxylin (37\%). The sections were analyzed under a light microscope (Olympus CX41), and the quantitation data were analyzed by Image Pro Plus software.

\section{Xenograft tumor studies}

All experimental procedures using animals were reviewed and approved by the Institutional Animal Care Committee at the Cancer Hospital of the Chinese Academy of Medical Science and our protocols followed the guidelines in China and the AAALAC protocol for the Care and Use of Animals in Research. Five- to six-week-old female BALB/C nude mice were provided by Beijing HFK Bioscience Co. Ltd (Beijing, China). A suspension of $1 \times 10^{6}$ KYSE150 cells in $0.1 \mathrm{~mL}$ saline was injected subcutaneously. The tumor volume was determined by caliper measurement of tumor length $(L)$ and width $(W)$ according to the formula $L W^{2} / 2$. Twenty nude mice with established tumors (all 150-200 $\mathrm{mm}^{3}$ ) were divided into four groups and treated with 1) vehicle (saline) alone; 2) a single dose of 10 Gy irradiation (IR); 3) YM155 alone ( $5 \mathrm{mg} / \mathrm{kg}$ as 7-day continuous intraperitoneal injections); or 4) YM155 plus IR (a single fraction of 10 Gy IR delivered on day 3 of drug treatment). X-ray radiation was delivered by a $6 \mathrm{MV}$ linear accelerator (Varian Medical Systems, Palo Alto, CA, USA) at a dose rate of $300 \mathrm{cGy} / \mathrm{min}$ with a source-totarget distance of $100 \mathrm{~cm}$. For tumor irradiation, animals were positioned to place the tumor in the center of a $1.0 \times 1.0 \mathrm{~cm}$ radiation field with the remaining mice being shielded from radiation. Body weight and tumor diameter were measured three times per week. The efficacy of each treatment was evaluated by the volume change during the treatment period. The first day of treatment was designed as day 0 , and observation continued until day 18. At the end of the observation, the mice were sacrificed, and the tumors were fixed in $10 \%$ formalin.

\section{Statistical analysis}

All data with error bars are presented as the mean \pm SD. The significance of differences between treatment and control mean values in all experiments was determined by the two-tailed Student's $t$-test, and $p<0.05$ was considered to be statistically significant. All calculations were performed using GraphPad Prism software. 


\section{Results}

YMI55 inhibited the upregulation of survivin induced by radiation

First, ESCC cells were treated with radiation, and Western blot analysis showed that survivin could be upregulated by 8 Gy radiation in all four ESCC cell lines (Figure 1A). The effect of YM155 on cell survival was evaluated. The CCK-8 assay showed that after 48 h of YM155 treatment, YM155 inhibited cell survival in a dose-dependent manner (Figure S1A). Then, the effect of YM155 on the survivin expression was evaluated; the effective inhibition concentration of YM155 varied in different cell lines (Figure S1B). Thus, the subtoxic concentrations of YM155 were chosen for treatment of the cells $(2,15,20$, and $30 \mathrm{nM}$ for KYSE150, KYSE410, KYSE180, and KYSE510, respectively) in the following experiments. Western blot analysis showed that the survivin protein decreased 48-72 h after YM155 treatment (Figure S1C). Moreover, YM155 inhibited survivin upregulation induced by radiation (Figure 1B). These results indicated that survivin was upregulated by radiation and that YM155 inhibited the upregulation.

\section{Radiosensitization of YMI 55 varied in different ESCC cell lines}

Next, the efficacy of YM155 as a radiosensitizer in ESCC cells was evaluated. The effect of YM155 on cell survival was assessed by the colony formation assay in a panel of four ESCC cell lines. Compared with the control cells, the survival fraction was significantly decreased after radiation combined with YM155 in the KYSE150 and KYSE410 cells (Figure 2A and B) but not in the KYSE180 and KYSE510 cells (Figure 2C and D). Therefore, YM155 could sensitize

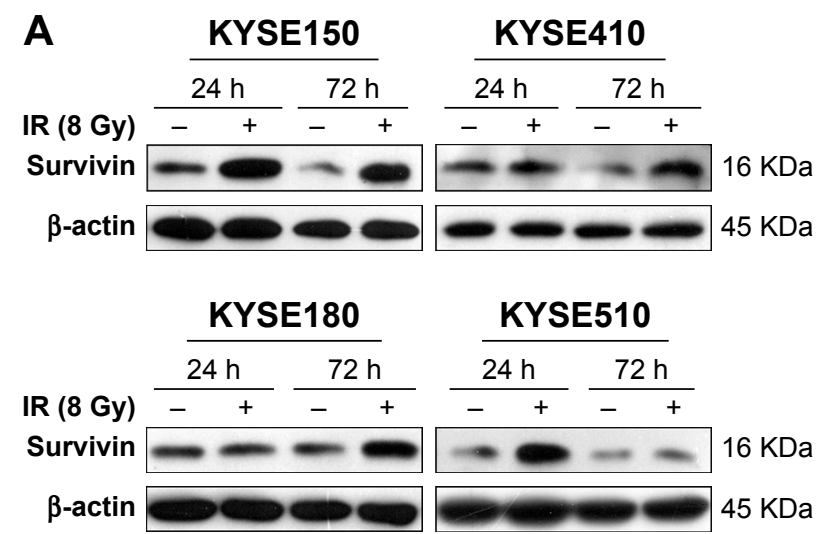

KYSE150 and KYSE410 cells to radiation, but combination with YM155 could not enhance the effect of radiation in KYSE180 and KYSE510 cells. These results for the first time indicated that the radiosensitization effect of YM155 varied in different ESCC cell lines.

\section{YMI55 could enhance radiosensitivity of ESCC cells when radiation induced senescence}

Cell senescence was checked by cytochemical detection of the activity of SA- $\beta$-Gal. The result showed that $53 \%$ of KYSE 150 and $65 \%$ of KYSE410 cells were SA- $\beta-G a l$ positive, $72 \mathrm{~h}$ after the $8 \mathrm{~Gy}$ irradiation. With the YM155 treatment, the SA- $\beta$-Gal positive cells decreased to $9 \%$ and $16 \%$ in the KYSE150 and KYSE410 cells, respectively (Figure 3A). Western blot analysis showed that p53 and p21 were upregulated after 8 Gy irradiation and that YM155 inhibited the upregulation (Figure 3B).

Additionally, cell apoptosis induced by radiation was detected. The TUNEL assay showed that radiation and YM155 could both induce apoptosis, but the combination of YM155 with radiation significantly increased the percentage of apoptotic cells from $24 \%$ to $69 \%$ for the KYSE150 cells and $18 \%$ to $65 \%$ for the KYSE410 cells (Figure 3C). PARP cleavage was significantly induced after YM155 treatment combined with radiation in the KYSE150 and the KYSE410 cells (Figure 3D). In agreement with the TUNEL assay result, Annexin V/PI staining showed that the combination of YM155 with radiation significantly increased the percentage of double-staining cells in the KYSE150 and KYSE410 cells (Figure 3E). These data indicated that YM155 could inhibit cell senescence and promote apoptosis of ESCC cells when radiation induced cell senescence.

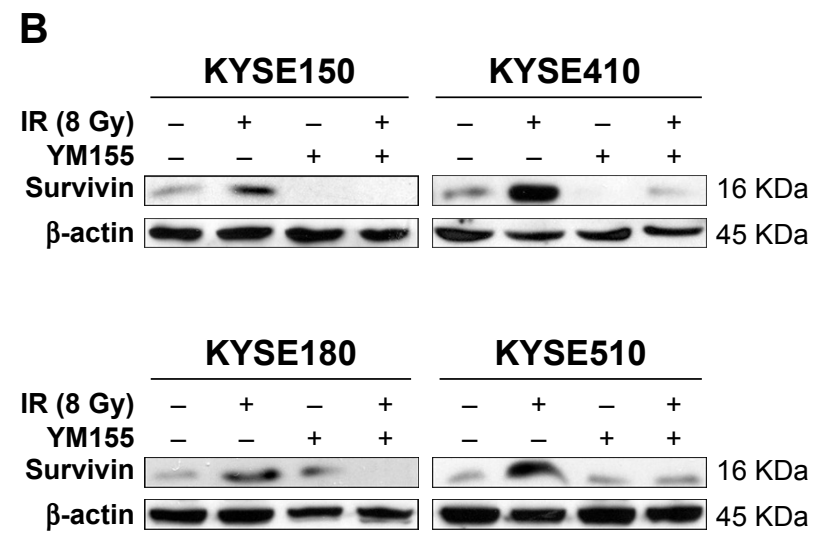

Figure I YMI55 inhibited the upregulation of survivin induced by radiation in ESCC cells. (A) ESCC cells were harvested and the cell lysates were subjected to immunoblot analysis with antibodies against survivin. (B) Survivin was detected $72 \mathrm{~h}$ after $8 \mathrm{~Gy}$ radiation with or without YMI55 treatment. $\beta$-actin was used as an internal control. Abbreviations: ESCC, esophageal squamous cell carcinoma; IR, irradiation. 
A

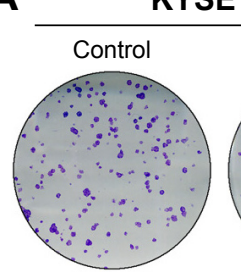

IR
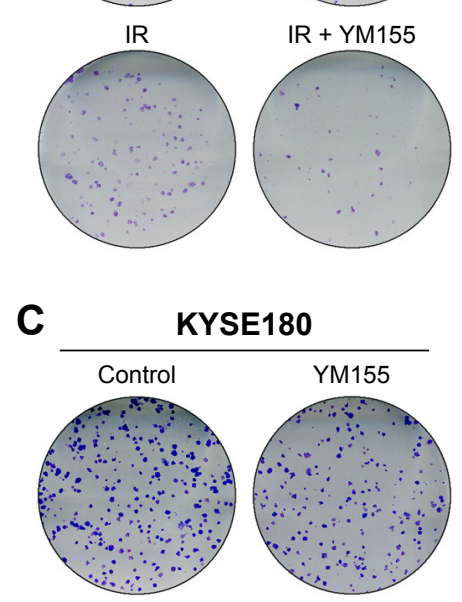

IR

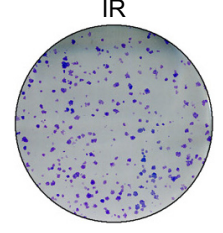

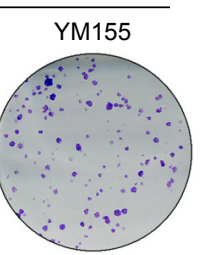

$\mathrm{IR}+\mathrm{YM} 155$

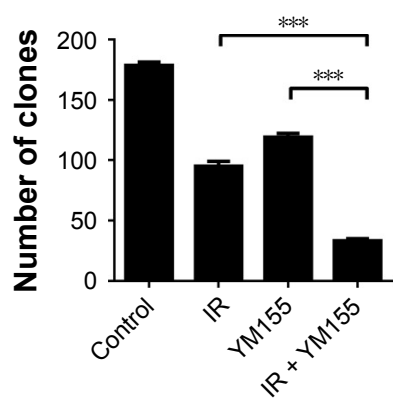

B
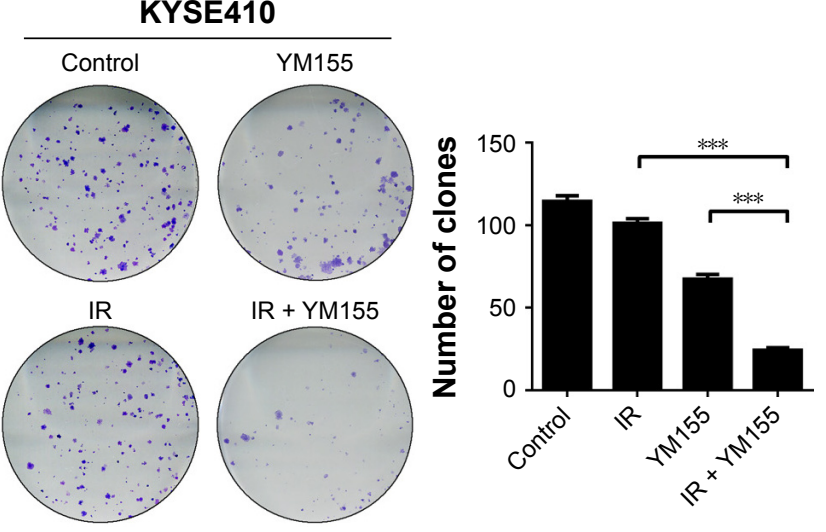

D
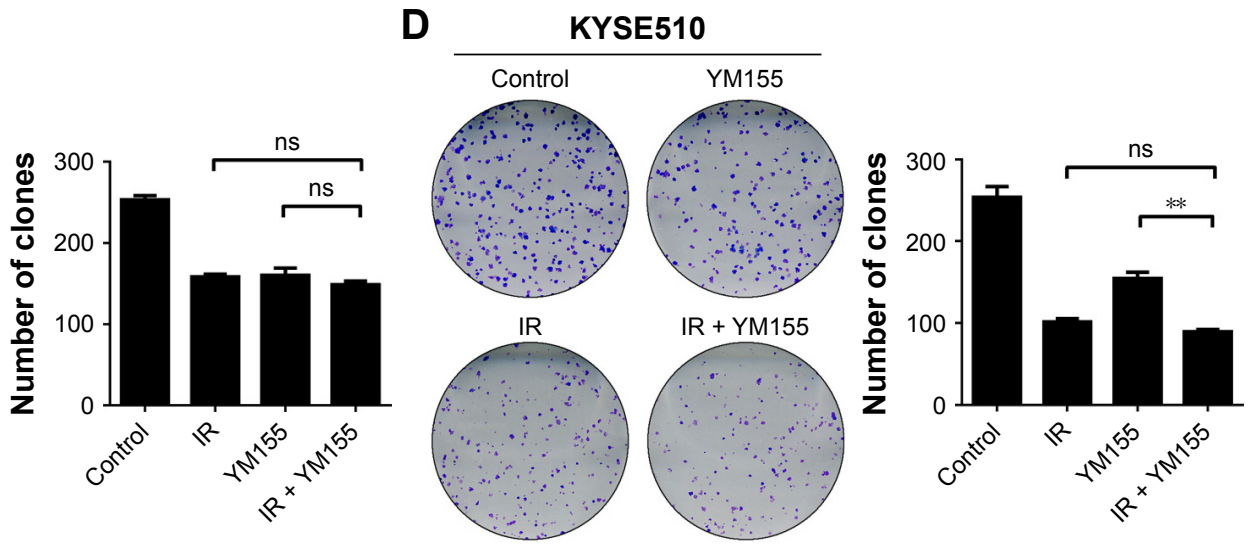

Figure 2 Radiosensitization of YMI55 varied in different ESCC cell lines. Long-time viability of cells was determined by the colony-formation assay. The cells were treated with YMI55, irradiated as illustrated and fixed after incubation for 10-14 days. The number of clones is shown in the histogram (right) (**p $<0.01$; **** $<0.001$ ). The data are represented as the mean from three independent experiments. (A) KYSEI50, (B) KYSE4I0, (C) KYSEI80, and (D) KYSE5I0. Values are represented as the mean \pm SD $(n=3)$ for each treatment.

Abbreviations: ESCC, esophageal squamous cell carcinoma; IR, irradiation; ns, not significant.

\section{YMI55 could not enhance}

\section{radiosensitivity of ESCC cells when} radiation did not induce senescence

Cell senescence was evaluated in the KYSE180 and KYSE510 cells, and few SA- $\beta$-Gal positive cells were observed after radiation (Figure 4A). Additionally, Western blot analysis showed no 553 or p 21 upregulation (Figure 4B). The TUNEL assay showed that radiation and YM155 could both induce apoptosis, but the combination of YM155 with radiation did not increase the percentage of apoptosis cells in the KYSE180 and KYSE510 cells (Figure 4C). The data suggest that when radiation did not induce senescence, as in the KYSE180 and KYSE510 cells, YM155 could not enhance radiosensitivity.

\section{YMI55 enhanced radiation-induced tumor inhibition of KYSEI50 cells in xenograft model}

To test the effects of the radiosensitivity of YM155 in vivo, KYSE150 cells were subcutaneously injected into nude mice.
After tumor formation, the mice were treated as described in the "Materials and methods" section. As shown in Figure 5A and $\mathrm{B}$, tumor volumes and tumor weights were significantly inhibited in the group treated with YM155 in combination with radiation. No significant body weight loss was observed in the mice treated with this combination compared with those treated with YM155 alone (Figure 5C). In agreement with the in vitro results, SA- $\beta$-Gal staining was observed after radiation, and the SA- $\beta$-Gal positive cells decreased in tumors treated with YM155 and radiation (Figure 5D). In contrast, the TUNEL assay showed that the combination of YM155 with radiation significantly increased the percentage of apoptosis (Figure 5E). Immunohistochemical analysis showed that $\mathrm{p} 53, \mathrm{p} 21$, and survivin were upregulated in irradiated tumor cells but inhibited when radiation was combined with the YM155 treatment (Figure 5F). These data show that radiation could induce cell senescence in the KYSE150 xenograft, and YM155 could enhance tumor inhibition by reducing senescence and promoting apoptosis. 
A

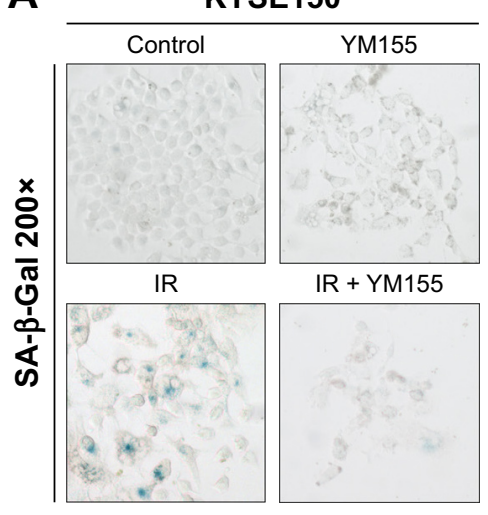

KYSE410

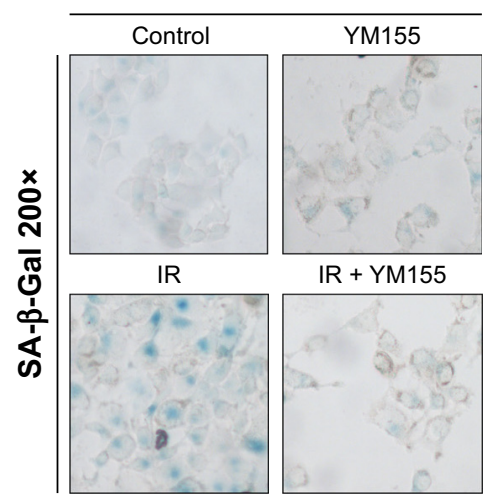

C
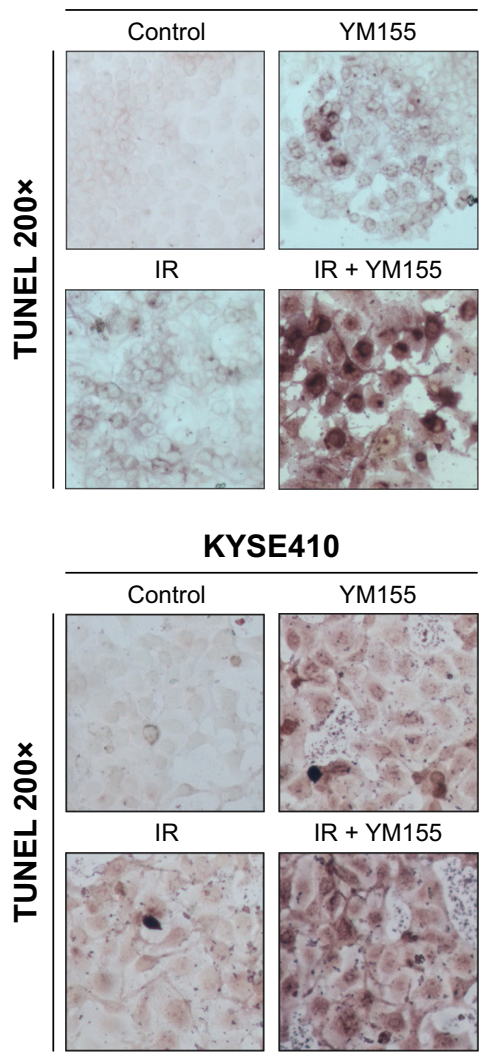
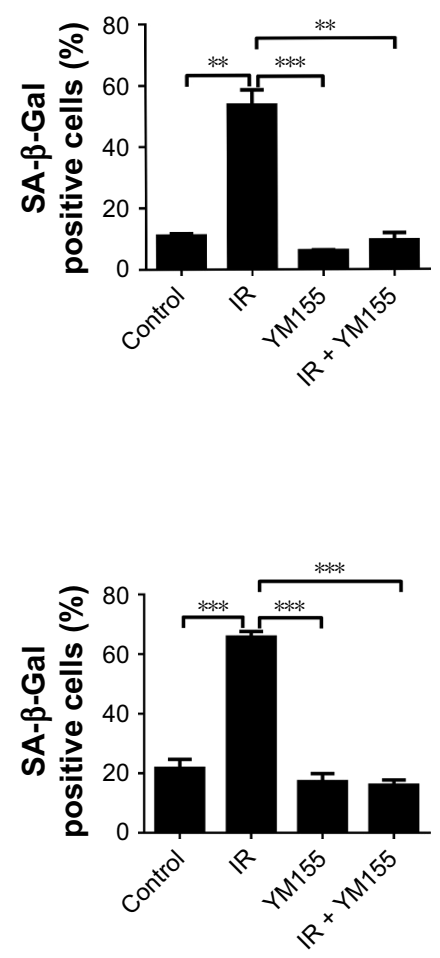

D
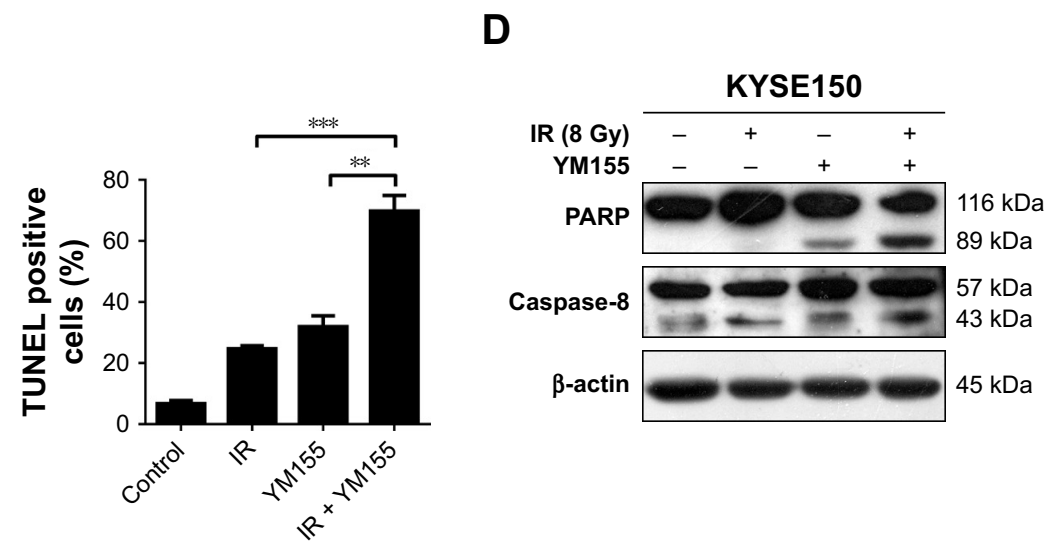

Figure 3 (Continued)

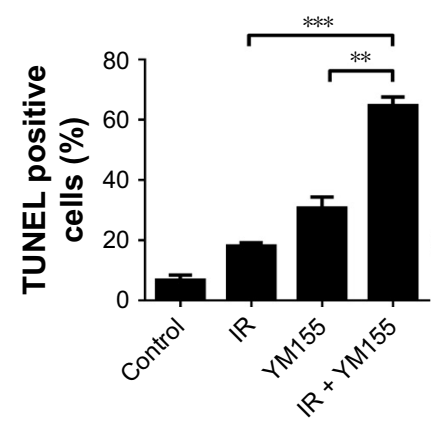

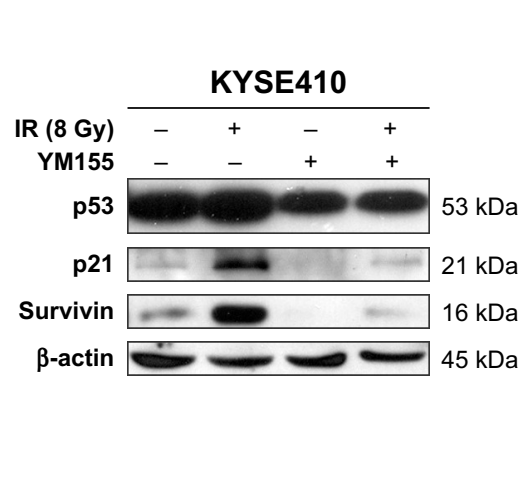

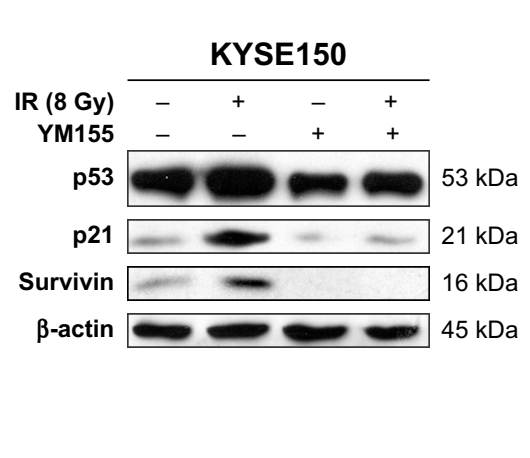

B

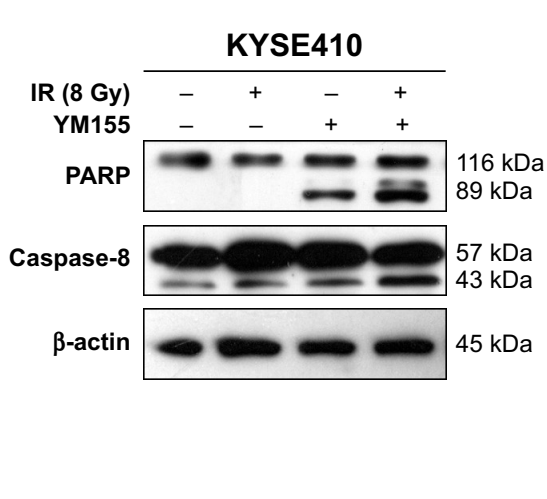



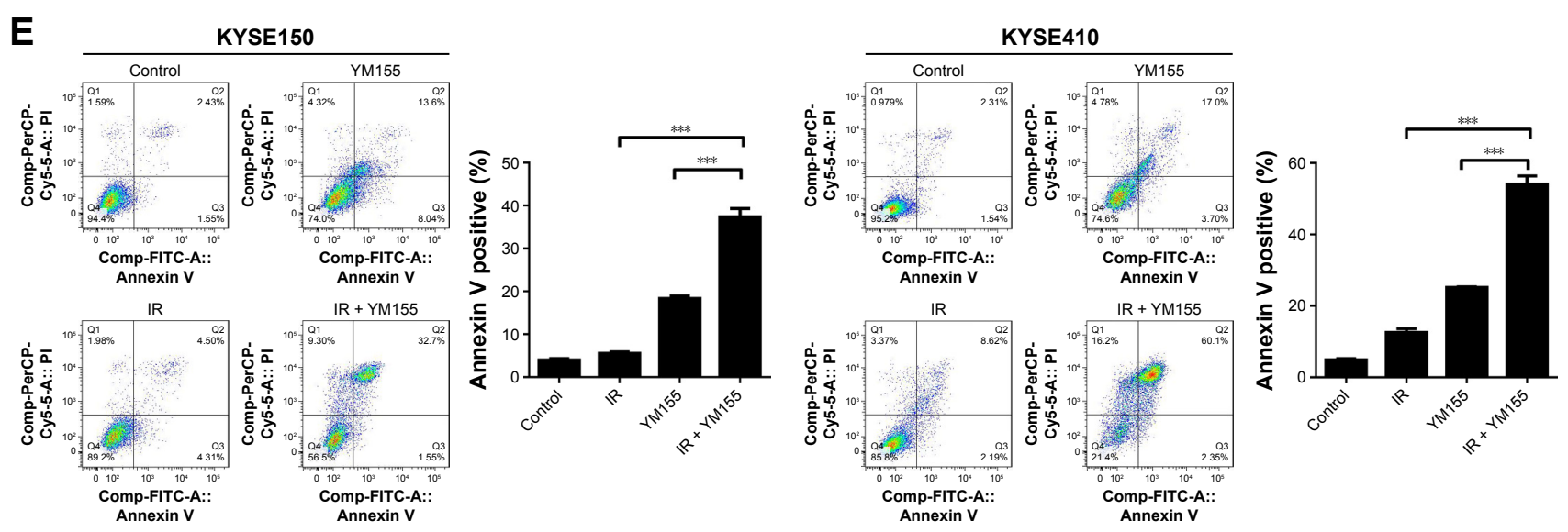

Figure 3 Radiation induced senescence in KYSEI50 and KYSE4I0 cells and YMI 55 reduced senescence but enhanced apoptosis. (A) Representative images of SA- $\beta$-Gal (green) staining for the KYSEI 50 and KYSE4I0 cells. The cells were treated with YMI55 I day before exposure to 8 Gy radiation. The cells were subjected to SA- $\beta$-Gal staining 3 days later; the quantifications are shown on the right. Values are represented as the mean $\pm S D(n=3)$ for each treatment $(* * p<0.0 I$, **** $p<0.00 \mathrm{I})$. (B) The protein levels of $\mathrm{p} 53, \mathrm{p} 2 \mathrm{I}$, and survivin in cells with or without treatment were evaluated by Western blotting, and $\beta$-actin was used as an internal control. (C) Representative images of TUNEL assay (purple) staining for the KYSEI50 and KYSE4I0 cells; the quantifications are shown on the right. Values are represented as the mean \pm SD ( $\mathrm{n}=3$ ) for each treatment (**p $<0.01$, ***p $<0.001$ ). (D) The protein levels of PARP and caspase-8 in cells with or without treatment were evaluated by Western blotting, and $\beta$-actin was used as an internal control. (E) The cells were stained by Annexin V/PI and analyzed by flow cytometry. Values are represented as the mean \pm SD ( $=3$ ) for each treatment $(* * * p<0.001)$.

Abbreviations: SA- $\beta$-Gal, senescence-associated $\beta$-galactosidase; TUNEL, terminal deoxynucleotidyl transferase-mediated dUTP nick end-labeling; PI, propidium iodide; PARP, poly ADP-ribose polymerase; FITC, fluorescein isothiocyanate; IR, irradiation.

\section{Radiosensitization of YMI55 was dependent on radiation-induced senescence}

To determine whether the radiosensitization of YM155 was dependent on radiation-induced senescence, pSilencer3.0H1shRNA-p21 was transfected into KYSE150 cells. As shown in Figure S2, p21 was inhibited in the KYSE150 cells before and after irradiation. SA- $\beta-G a l$ staining showed that the percentage of radiation-induced senescent cells decreased when p21 was inhibited (Figure 6A). Next, cell apoptosis was evaluated by using Annexin V-PI staining, and the result showed increased apoptosis in the p21-knockdown cells; however, the apoptotic ratio after radiation in the $\mathrm{p} 21$ knockdown KYSE150 cells showed no significant difference with or without YM155 treatment (Figure 6B). Therefore, p21 inhibition could enhance radiation-induced apoptosis, but YM155 could not enhance the radiation efficacy in the KYSE150 cells without radiation-induced senescence.

\section{Discussion}

Because of survivin's specific expression in cancer cells and correlation with poor prognosis of patients, this protein has been a very attractive therapeutic target in several types of cancers. Inhibition of survivin as a therapeutic strategy has been evaluated in in vitro and in vivo studies. ${ }^{19}$ In addition to targeting survivin alone in clinical trials, combination treatment with chemotherapy and radiotherapy has also been considered an attractive option. It has been reported that downregulation and inhibition of survivin could enhance the radiosensitivity of cancer cells. ${ }^{30,31}$

YM155, a small-molecule inhibitor of survivin, could sensitize cancer cells to radiation both in vitro and in vivo. ${ }^{24-26}$ Radiation could upregulate survivin in the ESCC cell lines TE4 and TE $8 .{ }^{32}$ In our study, survivin was upregulated by radiation in all ESCC cell lines; therefore, we used YM155 as a survivin inhibitor and confirmed that YM155 could inhibit the upregulation of survivin induced by radiation. But the radiosensitization effect of YM155 varied in different ESCC cell lines. This study is the first that demonstrates the difference in efficacy of YM155 in promoting the radiosensitivity of ESCC cells. Recently published data reported that YM155 could promote radiation-induced clonogenic cell death of Eca109 and TE3 cells, but the sensitization enhancement ratio of the two cell lines exhibited no large difference. ${ }^{24}$ Targeted therapy was only effective in specific conditions. For example, herceptin was used in breast cancer patients with ErbB2 overexpression; ${ }^{33}$ EGFR with specific mutations conferred sensitivity to gefitinib and erlotinib, ${ }^{34}$ and EGFR monoclonal antibody could be combined with radiotherapy when EGFR is overexpressed. ${ }^{35}$ A previous study showed that YM155 could suppress survivin expression and therefore inhibit the growth of cancer cells..$^{36,37}$ YM155 could reverse cisplatin resistance in head and neck cancer cells ${ }^{38}$ and enhance the sensitivity of docetaxel in human 
A
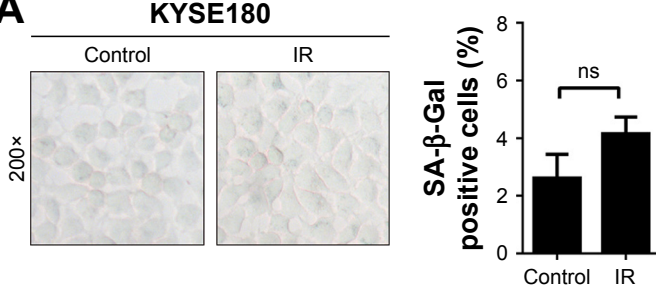

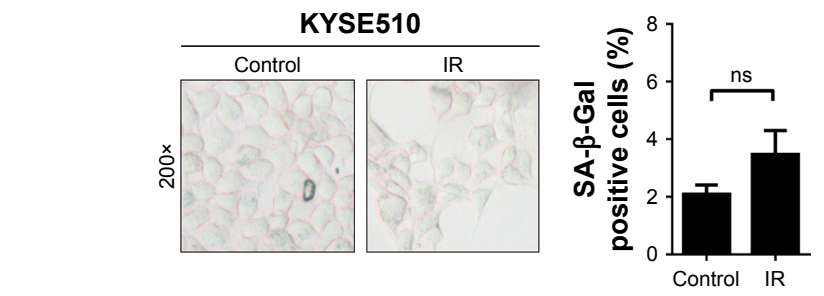

B

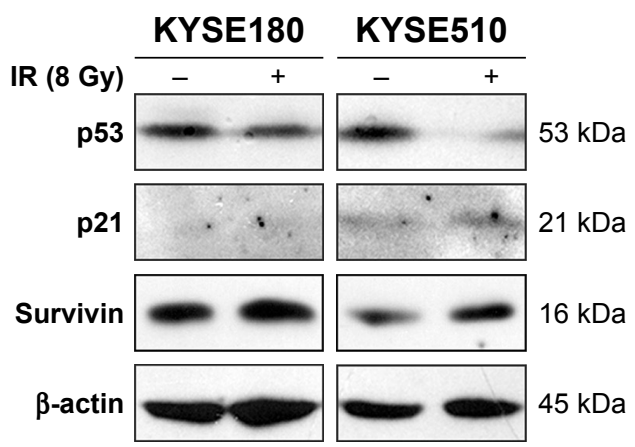

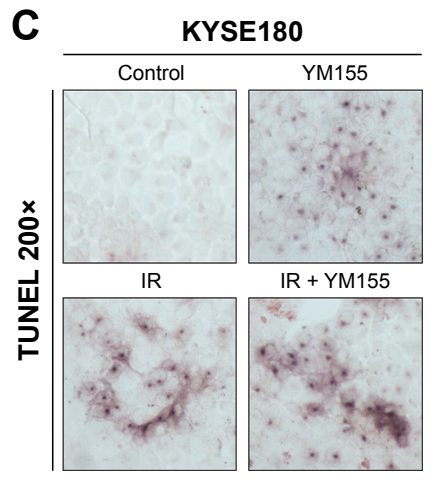
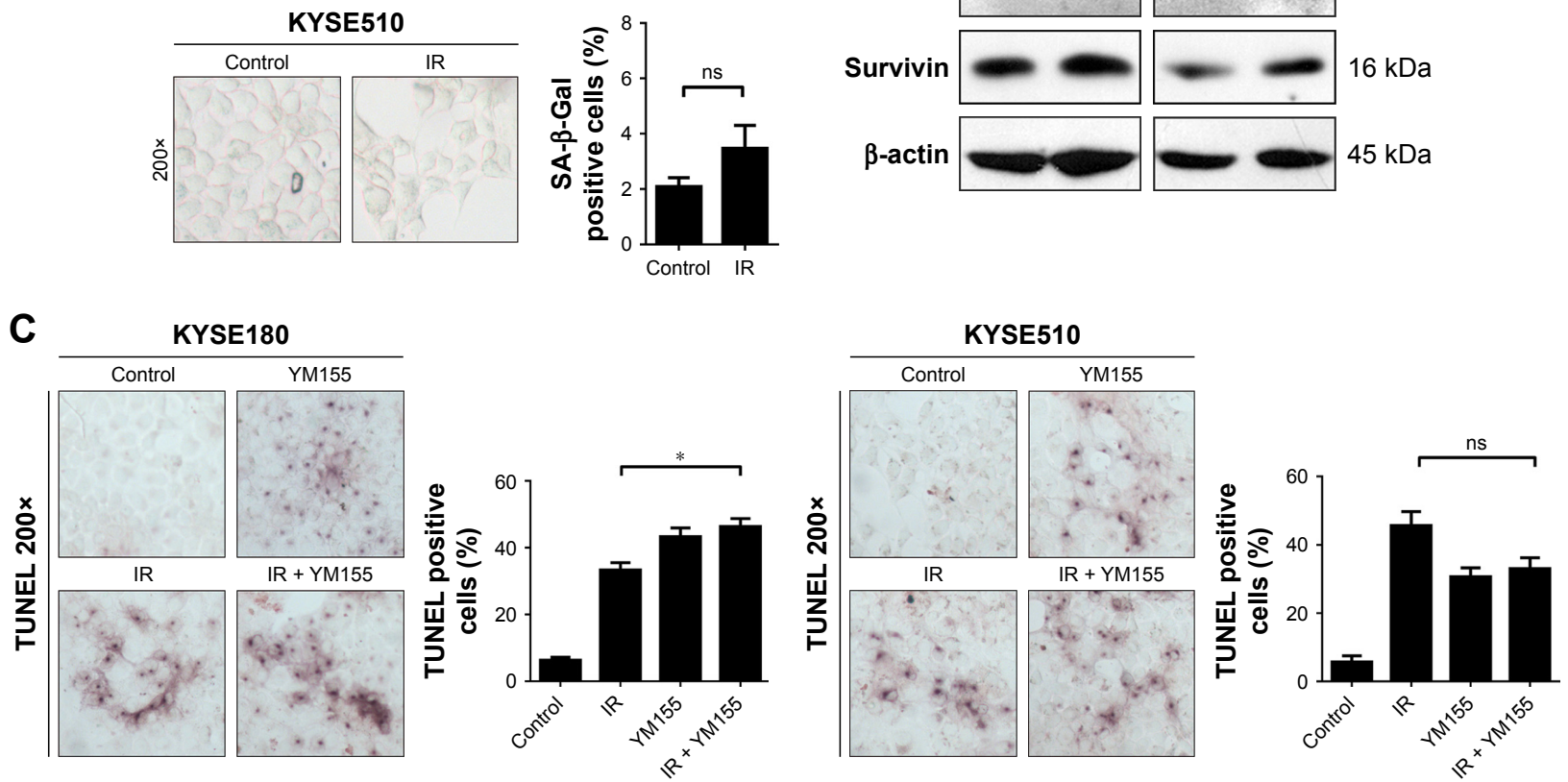

Figure 4 YMI 55 could not enhance apoptosis in KYSE5I0 and KYSEI80 cells. (A) Representative images of SA- $\beta$-Gal (green) staining for the KYSE5I0 and KYSEI80 cells. The cells were treated with YMI55 I day before exposure to 8 Gy radiation. The cells were subjected to SA- $\beta$-Gal staining 3 days later; the quantifications are shown on the right. Values are represented as the mean $\pm S D(n=3)$ for each treatment $(n s, p>0.05)$. (B) The protein levels of $p 53$, p2I, and survivin were evaluated by Western blotting. (C) Representative images of TUNEL assay (purple) staining for the KYSE5I0 and KYSEI80 cells; the quantifications are shown on the right. Values are represented as the mean $\pm S D(n=3)$ for each treatment $\left({ }^{*} p<0.05\right)$.

Abbreviations: SA- $\beta$-Gal, senescence-associated $\beta$-galactosidase; TUNEL, terminal deoxynucleotidyl transferase-mediated dUTP nick end-labeling; ns, not significant; IR, irradiation.

malignant melanoma models. ${ }^{39}$ Additionally, YM155 could enhance radiosensitization in ESCC and NSCLC cells. ${ }^{24-26}$ However, no study discussed differences in inhibition by YM155. Because we observed a difference in radiosensitization efficacy, we explored the mechanism and determined the cause of this difference. We have detected the expression of survivin in ESCC cell lines; ${ }^{40}$ however, the radiosensitization efficacy was not consistent with survivin expression. Therefore, we supposed that the radiosensitive efficiency of YM155 was not determined by survivin expression alone.

Depending on the level of DNA damage and cell type, radiation induces cell cycle arrest, DNA repair, senescence, or apoptosis. ${ }^{41}$ In our study, the apoptosis and senescence of ESCC cells was tested. We observed that YM155 could
A

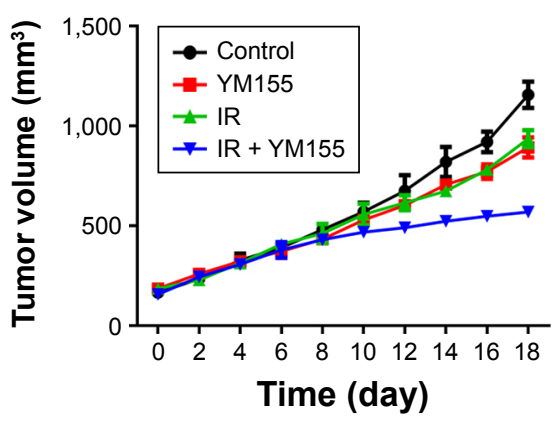

B

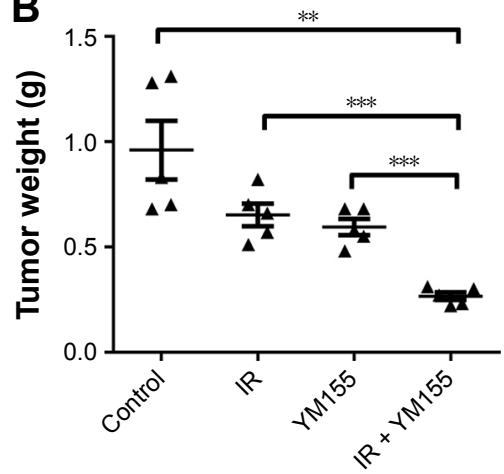

C

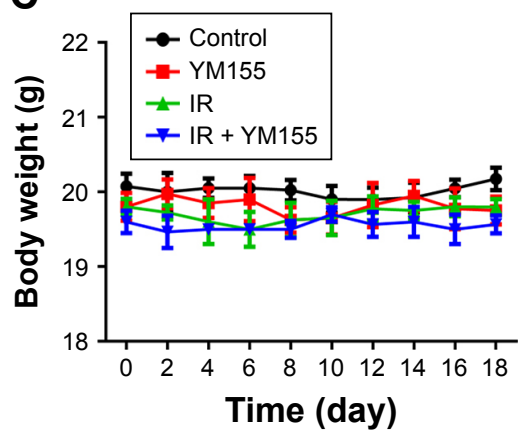

Figure 5 (Continued) 

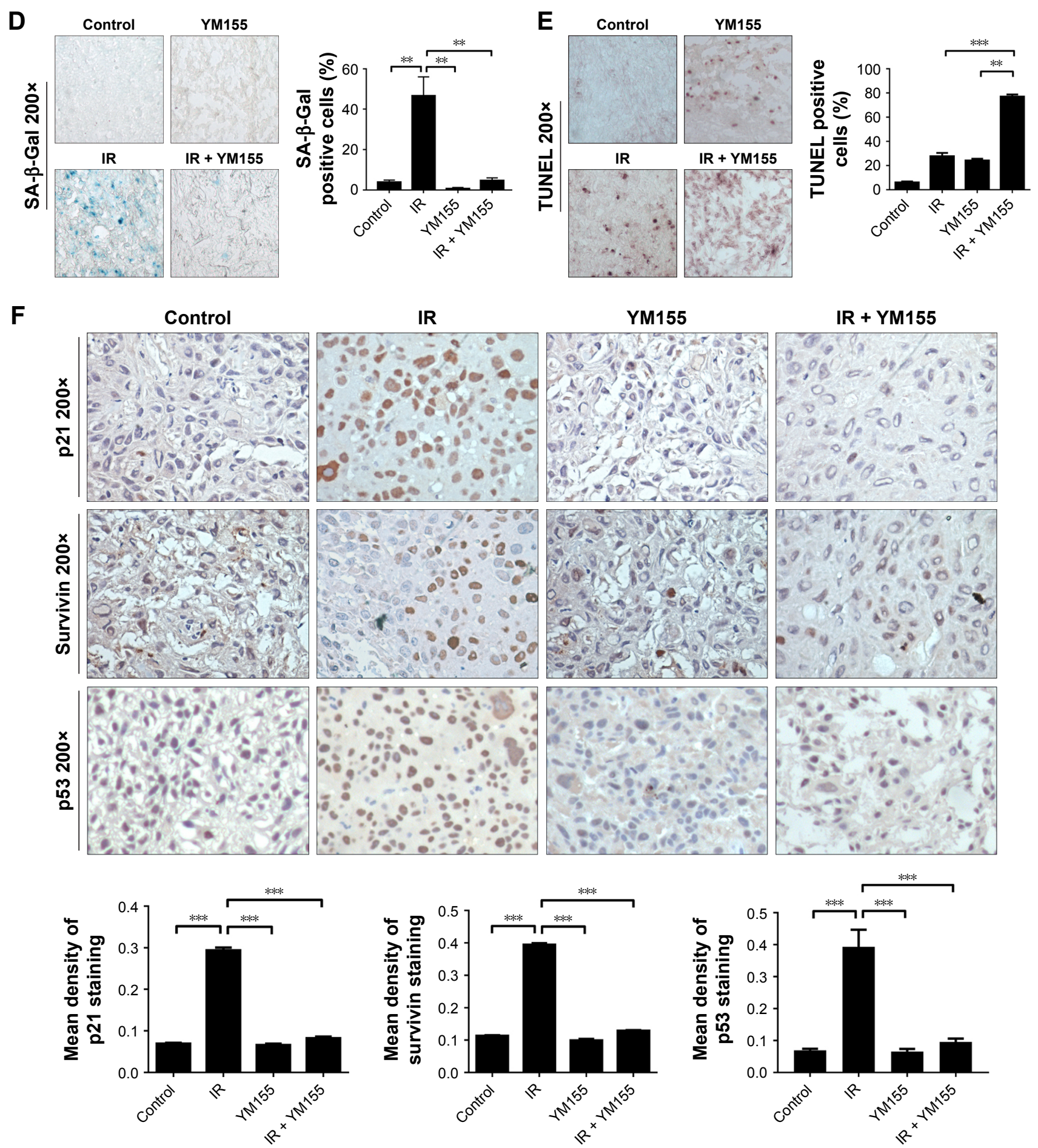

Figure 5 YMI55 could enhance radiosensitivity of KYSEI 50 xenografts. (A) Tumor volume was measured at the indicated times after the onset of treatment. Values are represented as the mean \pm SD from five mice per group. (B) The mice were sacrificed, and tumor weight was measured. Values are represented as the mean \pm SD from five mice per group. (C) Mice body weight was measured at the indicated times after the onset of treatment. (D) Representative images of SA- $\beta$-Gal (green) staining for tumor sections of different treatments; quantifications are shown on the right. (E) Representative images of TUNEL assay (purple) staining for tumor sections of different treatments; quantifications are shown on the right. (F) Immunohistochemistry analysis of p53, p2I, and survivin expression in tumor sections after different treatments; quantifications are shown below the images. $* * p<0.0$ I; *** $p<0.00$ I.

Abbreviations: SA- $\beta$-Gal, senescence-associated $\beta$-galactosidase; TUNEL, terminal deoxynucleotidyl transferase-mediated dUTP nick end-labeling; IR, irradiation.

promote radiosensitivity only when radiation induced senescence of ESCC cells. When the senescence pathway was inhibited by inhibiting p21 in the KYSE150 cells, the radiosensitization efficiency of YM155 was diminished.
These results suggested that survivin was important in radiation-induced senescence and that inhibition of survivin by YM155 could inhibit senescence and promote apoptosis of ESCC cells. In senescent cells treated with a low-dose 
A
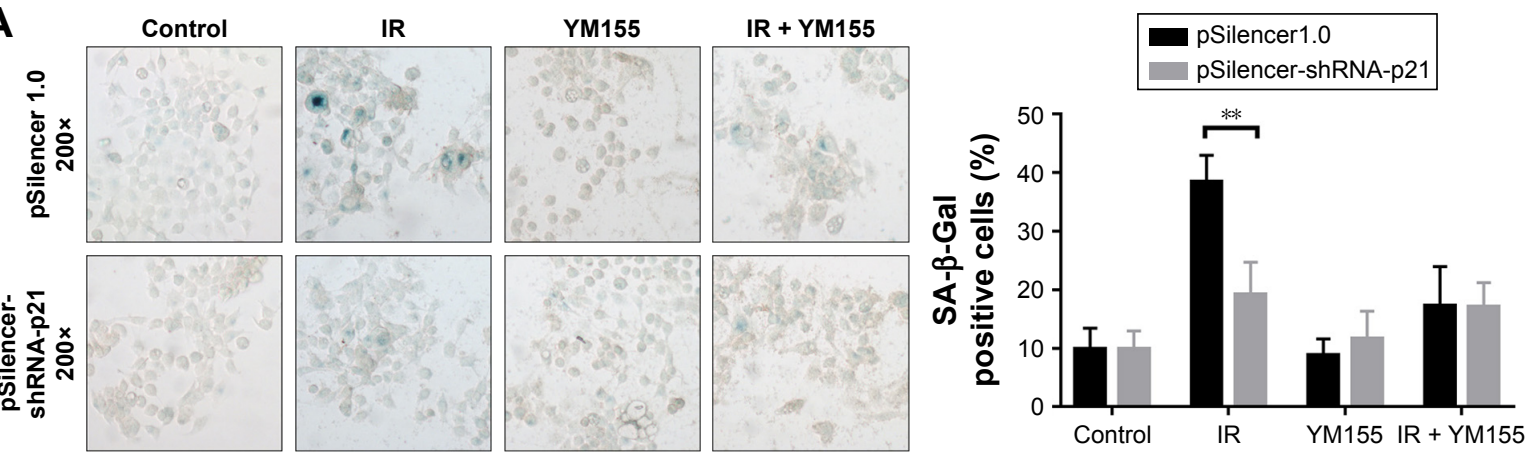

B

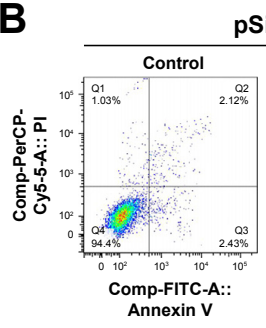

pSilencer1.0
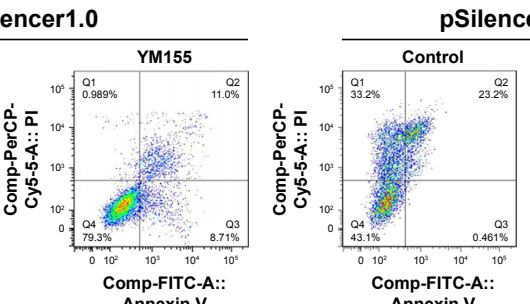

pSilencer-shRNA-p21
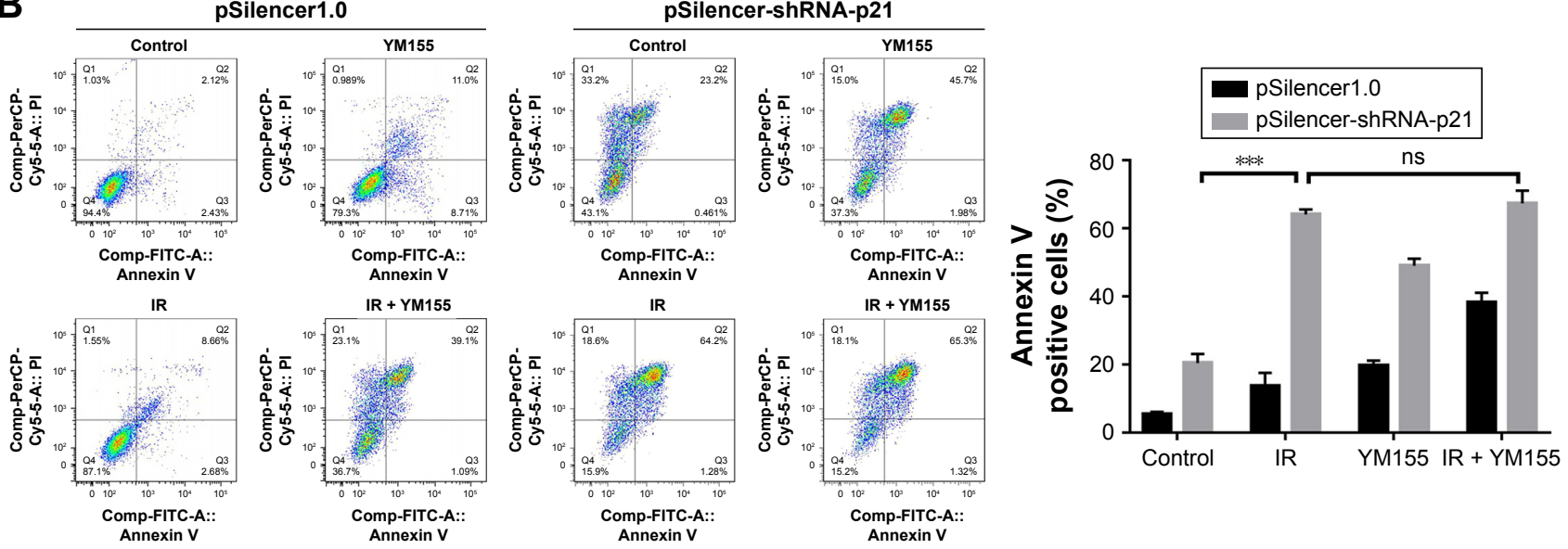

Annexin V

Figure 6 Knocking down the expression of p2I diminished the radiosensitization of YMI55 in KYSEI50 cells. (A) Representative images of SA- $\beta$-Gal (green) staining for KYSEI50 cells of different treatments; quantifications are shown on the right. (B) Representative images of Annexin V/PI staining for cells under different conditions; quantifications are shown on the right. ${ }^{*} p<0.01$; $* * * p<0.001$.

Abbreviations: SA- $\beta$-Gal, senescence-associated $\beta$-galactosidase; IR, irradiation; ns, not significant; PI, propidium iodide; FITC, fluorescein isothiocyanate.

doxorubicin, survivin was upregulated to maintain their survival by inhibiting apoptosis. ${ }^{42}$ An anti-survivin siRNA nanodrug (MN-siBIRC5) could enhance the therapeutic efficacy of low-dose doxorubicin when doxorubicin induced senescence-like morphological changes. ${ }^{43}$ Therefore, the major determinant of radiosensitization by YM155 could be the ability of radiation to induce senescence.

Cell senescence could be induced by several stimuli and is usually controlled by $\mathrm{p} 53$ or $\mathrm{p} 16-\mathrm{Rb}$ pathway. ${ }^{44}$ Ionizing radiation induced senescence primarily through the p53-p21 pathways. ${ }^{41,44,45}$ We observed that $\mathrm{p} 53$ and $\mathrm{p} 21$ were upregulated in radiation-induced senescent cells, but there was no significant $\mathrm{p} 16$ upregulation. The result indicated that senescence induced by 8 Gy radiation in ESCC cells mainly depended on the p53-p21 pathways. When p21 protein upregulation was inhibited by RNAi, radiation did not induce senescence in the KYSE150 cells, and the radiosensitization efficiency of YM155 was diminished.

p53 status in cancer cells could determine the response of cancer therapy. ${ }^{46,47}$ It is generally accepted that tumors with wild-type p53 show a p53-mediated senescence response to DNA damage. ${ }^{48-50}$ Disruptive TP53 mutations increased radioresistance via the inhibition of senescence in headneck squamous cell carcinoma tumors. ${ }^{51}$ Cells with mutant p53 underwent mitotic catastrophe and apoptosis after chemotherapy. ${ }^{52}$ After sequenced p53 exons of ESCC cells used in our study, we observed deletion mutations in exon7 of p53 in KYSE510 and KYSE180 cells, leading to amino acid deletion in the DNA binding site of the p53 protein (data not shown). According to our results, KYSE150 and KYSE410 attained senescence after radiation, but the KYSE510 and KYSE180 cells did not. Therefore, we could suppose that the cells of patients with wide-type p53 were more likely to be induced to senescence and might show better response to YM155 treatment combined with radiation. Although additional studies are required to test the correlation of p53 status and the radiosensitive efficiency of YM155, our study has discussed a potential strategy of combining YM155 treatment with radiotherapy in ESCC patients.

\section{Conclusion}

We found the efficacy of YM155 radiosensitizing activity varied in different ESCC cell lines and the difference was not determined by survivin expression only. Our results suggest 
a new pathway through which YM155 could partially sensitize ESCC cells to radiation by inhibiting radiation-induced senescence and enhancing apoptosis. The major determinant of radiosensitization by YM155 might be the induction of senescence by radiation.

\section{Acknowledgments}

This work was supported by the National Natural Science Foundation (31171322, 81272512, 81321091) and CAMS Innovation Fund for Medical Sciences (2016-I2M-1-001).

\section{Author contributions}

$\mathrm{HZ}$ conceived the idea of the project and designed most of the experiments. XL conducted most of the experiments, analyzed the results, and wrote the paper. $\mathrm{YZ}$ is the main designer of animal experiment. $\mathrm{MH}$ contributed to the preparation of figures. WZ and YG provided a lot of experience and intellectual support in the process of the experiment. ML, ZX, NX, and SL provided expertise and feedback. All authors contributed toward data analysis, drafting and critically revising the paper and agree to be accountable for all aspects of the work. All authors approved the final submitted version.

\section{Disclosure}

The authors report no conflicts of interest in this work.

\section{References}

1. Chen W, Zheng R, Baade PD, et al. Cancer statistics in China, 2015. CA Cancer J Clin. 2016;66(2):115-132.

2. Mariette C, Piessen G, Triboulet JP. Therapeutic strategies in oesophageal carcinoma: role of surgery and other modalities. Lancet Oncol. 2007;8(6):545-553.

3. Ohashi S, Miyamoto S, Kikuchi O, Goto T, Amanuma Y, Muto M. Recent advances from basic and clinical studies of esophageal squamous cell carcinoma. Gastroenterology. 2015;149(7):1700-1715.

4. Goense L, van Rossum PS, Kandioler D, et al. Stage-directed individualized therapy in esophageal cancer. Ann N Y Acad Sci. 2016; 1381(1):50-65.

5. Deloch L, Derer A, Hartmann J, Frey B, Fietkau R, Gaipl US. Modern radiotherapy concepts and the impact of radiation on immune activation. Front Oncol. 2016;6:141.

6. Zhang J, Shen L, Sun LQ. The regulation of radiosensitivity by $\mathrm{p} 53$ and its acetylation. Cancer Lett. 2015;363(2):108-118.

7. Saki M, Makino H, Javvadi P, et al. EGFR mutations compromise hypoxia-associated radiation resistance through impaired replication fork-associated DNA damage repair. Mol Cancer Res. 2017;15(11): 1503-1516.

8. Mueller AK, Lindner K, Hummel R, Haier J, Watson DI, Hussey DJ. MicroRNAs and their impact on radiotherapy for cancer. Radiat Res. 2016;185(6):668-677.

9. Derer A, Frey B, Fietkau R, Gaipl US. Immune-modulating properties of ionizing radiation: rationale for the treatment of cancer by combination radiotherapy and immune checkpoint inhibitors. Cancer Immunol Immunother. 2016;65(7):779-786.

10. Park M, Yoon HJ, Kang MC, Kwon J, Lee HW. MiR-338-5p enhances the radiosensitivity of esophageal squamous cell carcinoma by inducing apoptosis through targeting survivin. Sci Rep. 2017;7(1):10932.
11. Chen YF, Cho JJ, Huang TH, Tseng CN, Huang EY, Cho CL. Downregulation of a novel human gene, ROGDI, increases radiosensitivity in cervical cancer cells. Cancer Biol Ther. 2016:1-9.

12. Ding YQ, Zhu HC, Chen XC, et al. Sunitinib modulates the radiosensitivity of esophageal squamous cell carcinoma cells in vitro. Dis Esophagus. 2016;29(8):1144-1151.

13. Seong da B, Hong S, Muthusami S, Kim WD, Yu JR, Park WY. Cordycepin increases radiosensitivity in cervical cancer cells by overriding or prolonging radiation-induced G2/M arrest. Eur J Pharmacol. 2016;771:77-83.

14. Altieri DC. Survivin, versatile modulation of cell division and apoptosis in cancer. Oncogene. 2003;22(53):8581-8589.

15. Wang Q, Wu PC, Roberson RS, et al. Survivin and escaping in therapyinduced cellular senescence. Int J Cancer. 2011;128(7):1546-1558.

16. Altieri DC. Validating survivin as a cancer therapeutic target. Nat Rev Cancer. 2003;3(1):46-54.

17. Rodel F, Hoffmann J, Distel L, et al. Survivin as a radioresistance factor, and prognostic and therapeutic target for radiotherapy in rectal cancer. Cancer Res. 2005;65(11):4881-4887.

18. Altieri DC. Survivin, cancer networks and pathway-directed drug discovery. Nat Rev Cancer. 2008;8(1):61-70.

19. Peery RC, Liu JY, Zhang JT. Targeting survivin for therapeutic discovery: past, present, and future promises. Drug Discov Today. 2017; 22(10):1466-1477.

20. Cheng Q, Ling X, Haller A, et al. Suppression of survivin promoter activity by YM155 involves disruption of Sp1-DNA interaction in the survivin core promoter. Int J Biochem Mol Biol. 2012;3(2):179-197.

21. Giaccone G, Zatloukal P, Roubec J, et al. Multicenter phase II trial of YM155, a small-molecule suppressor of survivin, in patients with advanced, refractory, non-small-cell lung cancer. J Clin Oncol. 2009; 27(27):4481-4486.

22. Clemens MR, Gladkov OA, Gartner E, et al. Phase II, multicenter, open-label, randomized study of YM155 plus docetaxel as first-line treatment in patients with HER2-negative metastatic breast cancer. Breast Cancer Res Treat. 2015;149(1):171-179.

23. Kudchadkar R, Ernst S, Chmielowski B, et al. A phase 2, multicenter, open-label study of sepantronium bromide (YM155) plus docetaxel in patients with stage III (unresectable) or stage IV melanoma. Cancer Med. 2015;4(5):643-650.

24. Qin Q, Cheng H, Lu J, et al. Small-molecule survivin inhibitor YM155 enhances radiosensitization in esophageal squamous cell carcinoma by the abrogation of G2 checkpoint and suppression of homologous recombination repair. J Hematol Oncol. 2014;7:62.

25. Iwasa T, Okamoto I, Suzuki M, et al. Radiosensitizing effect of YM155, a novel small-molecule survivin suppressant, in non-small cell lung cancer cell lines. Clin Cancer Res. 2008;14(20):6496-6504.

26. Hu S, Fu S, Xu X, et al. The mechanism of radiosensitization by YM155, a novel small molecule inhibitor of survivin expression, is associated with DNA damage repair. Cell Physiol Biochem. 2015;37(3):1219-1230.

27. Zhu H, Wang Q, Hu C, et al. High expression of survivin predicts poor prognosis in esophageal squamous cell carcinoma following radiotherapy. Tumour Biol. 2011;32(6):1147-1153.

28. Shimada Y, Imamura M, Wagata T, Yamaguchi N, Tobe T. Characterization of 21 newly established esophageal cancer cell lines. Cancer. 1992;69(2):277-284.

29. Zhang J, Lou X, Yang S, et al. BAG2 is a target of the c-Myc gene and is involved in cellular senescence via the p21(CIP1) pathway. Cancer Lett. 2012;318(1):34-41.

30. Hu J, Pan J, Luo Z, Tao Z. Downregulation of survivin by shRNA inhibits invasion and enhances the radiosensitivity of laryngeal squamous cell carcinoma. Cell Biochem Biophys. 2015;72(1):251-257.

31. Ferreiro-Neira I, Torres NE, Liesenfeld LF, et al. XPO1 inhibition enhances radiation response in preclinical models of rectal cancer. Clin Cancer Res. 2016;22(7):1663-1673.

32. Sugase T, Takahashi T, Serada S, et al. SOCS1 gene therapy improves radiosensitivity and enhances irradiation-induced DNA damage in esophageal squamous cell carcinoma. Cancer Res. 2017;77(24):6975-6986. 
33. Shak S. Overview of the trastuzumab (Herceptin) anti-HER2 monoclonal antibody clinical program in HER2-overexpressing metastatic breast cancer. Herceptin Multinational Investigator Study Group. Semin Oncol. 1999;26(4 Suppl 12):71-77.

34. Riely GJ, Pao W, Pham D, et al. Clinical course of patients with nonsmall cell lung cancer and epidermal growth factor receptor exon 19 and exon 21 mutations treated with gefitinib or erlotinib. Clin Cancer Res. 2006;12(3 Pt 1):839-844.

35. Basavaraj C, Sierra P, Shivu J, Melarkode R, Montero E, Nair P. Nimotuzumab with chemoradiation confers a survival advantage in treatment-naive head and neck tumors over expressing EGFR. Cancer Biol Ther. 2010;10(7):673-681.

36. Nakahara T, Kita A, Yamanaka K, et al. YM155, a novel small-molecule survivin suppressant, induces regression of established human hormonerefractory prostate tumor xenografts. Cancer Res. 2007;67(17): 8014-8021.

37. Kita A, Nakahara T, Yamanaka K, et al. Antitumor effects of YM155, a novel survivin suppressant, against human aggressive non-Hodgkin lymphoma. Leuk Res. 2011;35(6):787-792.

38. Kumar B, Yadav A, Lang JC, et al. YM155 reverses cisplatin resistance in head and neck cancer by decreasing cytoplasmic survivin levels. Mol Cancer Ther. 2012;11(9):1988-1998.

39. Yamanaka K, Nakahara T, Yamauchi T, et al. Antitumor activity of YM155, a selective small-molecule survivin suppressant, alone and in combination with docetaxel in human malignant melanoma models. Clin Cancer Res. 2011;17(16):5423-5431.

40. Wang Y, Zhu H, Quan L, et al. Downregulation of survivin by RNAi inhibits the growth of esophageal carcinoma cells. Cancer Biol Ther. 2005;4(9):974-978.

41. Eriksson D, Stigbrand T. Radiation-induced cell death mechanisms. Tumour Biol. 2010;31(4):363-372.

42. Ma K, Xu Q, Wang S, et al. Nuclear accumulation of Yes-Associated Protein (YAP) maintains the survival of doxorubicin-induced senescent cells by promoting survivin expression. Cancer Lett. 2016;375(1): 84-91.
43. Ghosh SK, Yigit MV, Uchida M, et al. Sequence-dependent combination therapy with doxorubicin and a survivin-specific small interfering RNA nanodrug demonstrates efficacy in models of adenocarcinoma. Int J Cancer. 2014;134(7):1758-1766.

44. Campisi J, d'Adda di Fagagna F. Cellular senescence: when bad things happen to good cells. Nat Rev Mol Cell Biol. 2007;8(9):729-740.

45. Mirzayans R, Andrais B, Scott A, Murray D. New insights into p53 signaling and cancer cell response to DNA damage: implications for cancer therapy. J Biomed Biotechnol. 2012;2012:170325.

46. Mirzayans R, Andrais B, Scott A, Wang YW, Murray D. Ionizing radiation-induced responses in human cells with differing TP53 status. Int J Mol Sci. 2013;14(11):22409-22435.

47. Bieging KT, Mello SS, Attardi LD. Unravelling mechanisms of p53mediated tumour suppression. Nat Rev Cancer. 2014;14(5):359-370.

48. Tonnessen-Murray CA, Lozano G, Jackson JG. The regulation of cellular functions by the p53 protein: cellular senescence. Cold Spring Harb Perspect Med. 2017;7(2). pii:a026112.

49. Widel M, Lalik A, Krzywon A, Poleszczuk J, Fujarewicz K, Rzeszowska-Wolny J. The different radiation response and radiationinduced bystander effects in colorectal carcinoma cells differing in p53 status. Mutat Res. 2015;778:61-70.

50. Mirzayans R, Scott A, Cameron M, Murray D. Induction of accelerated senescence by gamma radiation in human solid tumor-derived cell lines expressing wild-type TP53. Radiat Res. 2005;163(1):53-62.

51. Skinner HD, Sandulache VC, Ow TJ, et al. TP53 disruptive mutations lead to head and neck cancer treatment failure through inhibition of radiation-induced senescence. Clin Cancer Res. 2012;18(1):290-300.

52. Varna M, Lehmann-Che J, Turpin E, et al. p53 dependent cell-cycle arrest triggered by chemotherapy in xenografted breast tumors. Int $J$ Cancer. 2009;124(4):991-997. 


\section{Supplementary materials}

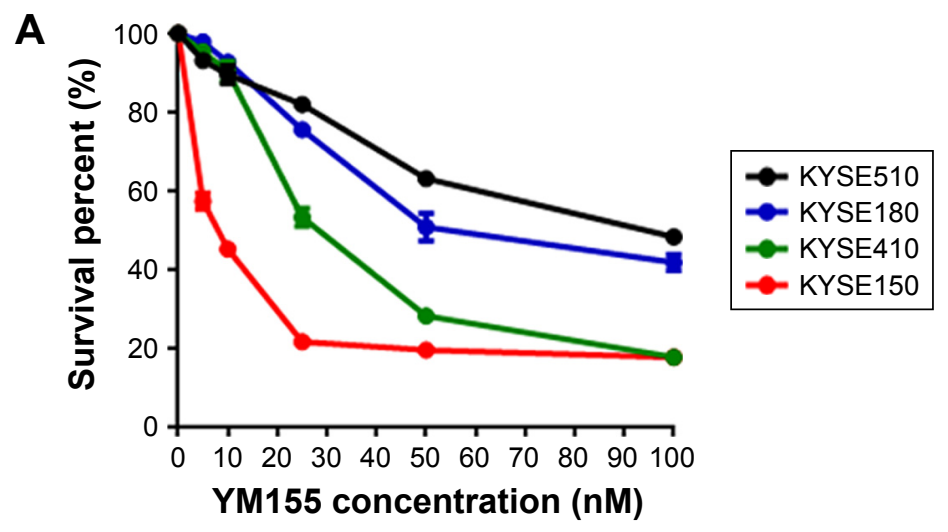

B
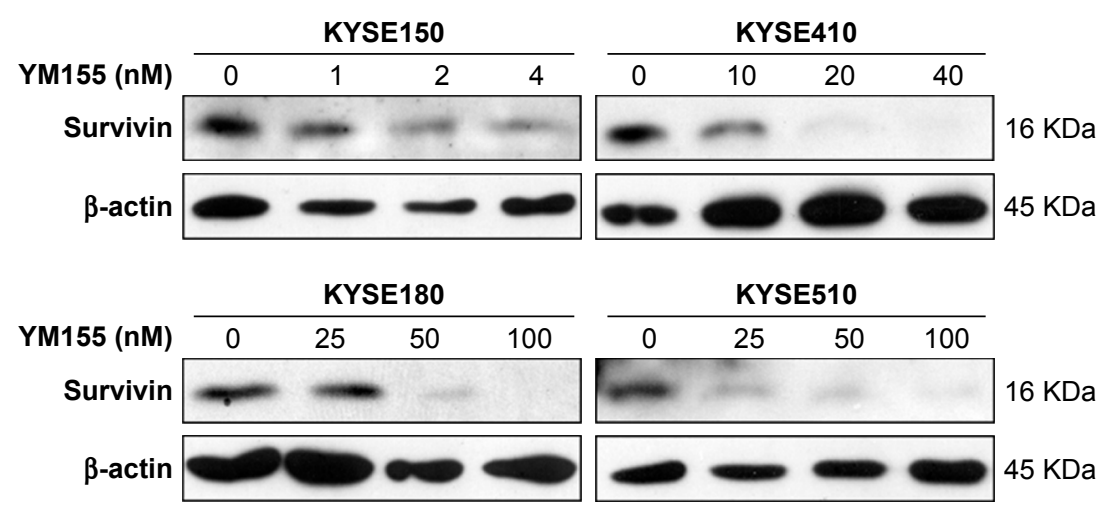

C
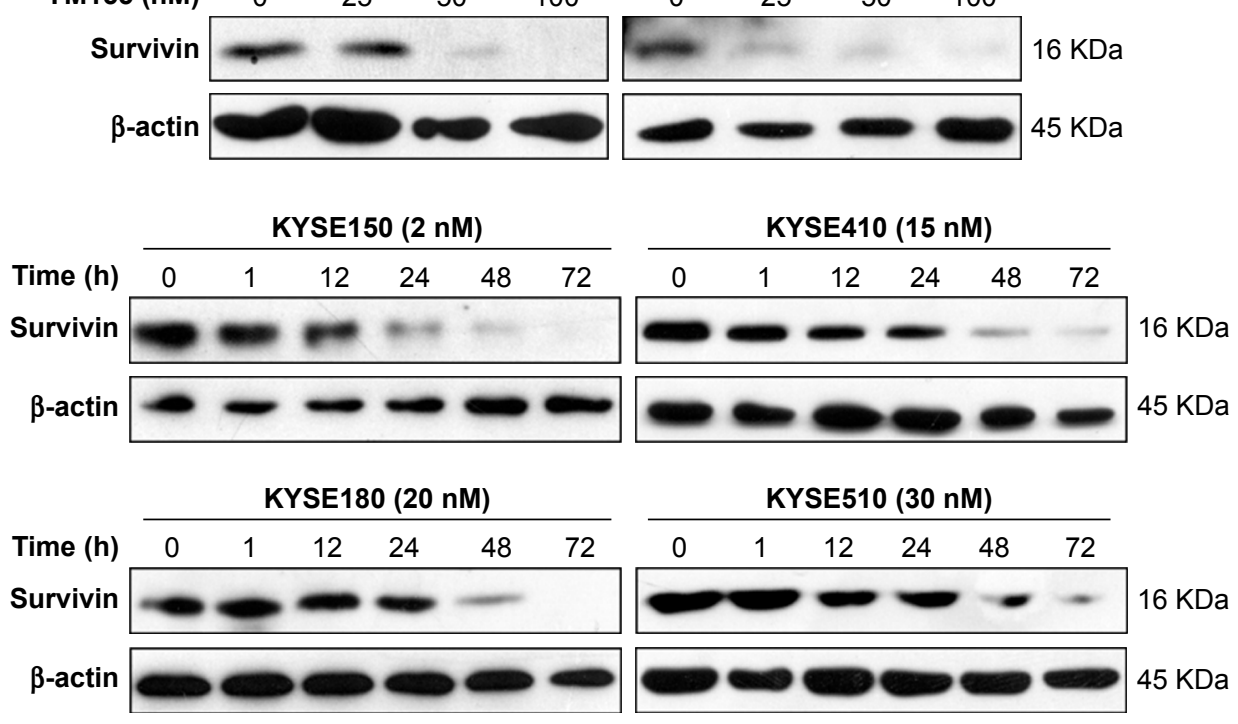

Figure SI YMI 55 suppressed protein levels of survivin in a dose-dependent and time-dependent manner in human ESCC cells. (A) Dose-response curve for four ESCC cell lines after YMI 55 treatment for $48 \mathrm{~h}$. The survival curves of these cells were constructed by CCK-8 assay. (B) ESCC cells were treated with the indicated concentrations of YMI55 for $48 \mathrm{~h}$ and then total cell lysates were assayed for survivin by Western blotting. (C) ESCC cells were treated with YMI 55 for the indicated times, and the expression of survivin was analyzed by immunoblotting. $\beta$-actin was used as an internal control.

Abbreviations: ESCC, esophageal squamous cell carcinoma; CCK-8, cell-counting kit-8. 


\section{Control}

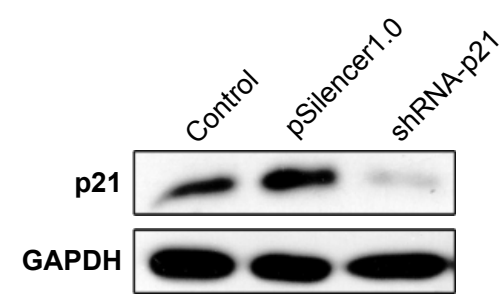

IR

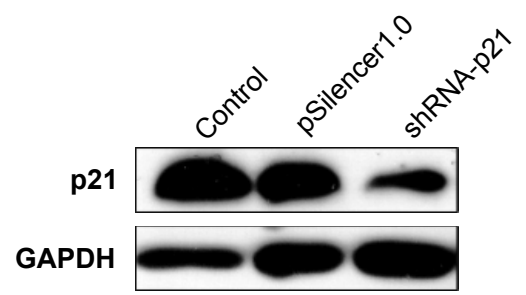

YM155

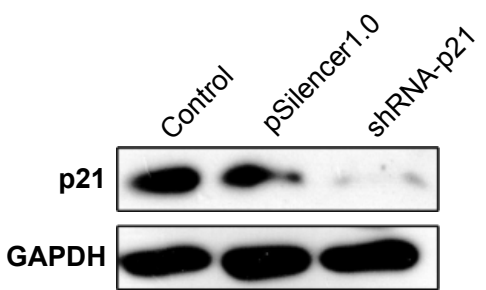

IR+YM155

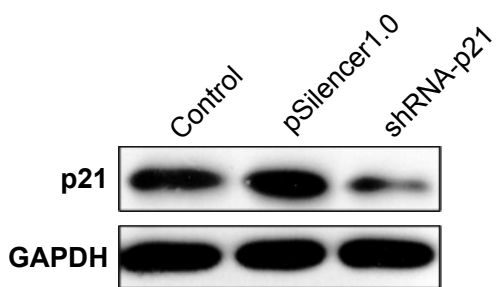

Figure S2 Knocked down p2I expression in KYSEI50 cells. KYSEI50 cells were transfected with pSilencer3.0HI-shRNA-p2I and p2I protein was evaluated by Western blotting.

Abbreviations: IR, irradiation; GADPH, glyceraldehyde-3-phosphate dehydrogenase.

\section{Publish your work in this journal}

OncoTargets and Therapy is an international, peer-reviewed, open access journal focusing on the pathological basis of all cancers, potential targets for therapy and treatment protocols employed to improve the management of cancer patients. The journal also focuses on the impact of management programs and new therapeutic agents and protocols on patient perspectives such as quality of life, adherence and satisfaction. The manuscript management system is completely online and includes a very quick and fair peer-review system, which is all easy to use. Visit http://www.dovepress.com/testimonials.php to read real quotes from published authors. 